\title{
In vitro differentiation of germ cells from stem cells: a comparison between primordial germ cells and in vitro derived primordial germ cell-like cells
}

\author{
W Ge ${ }^{1,2,4}, C$ Chen ${ }^{1,2,4}$, M De Felicic ${ }^{*, 3}$ and W Shen ${ }^{*, 1,2}$
}

Stem cells are unique cell types capable to proliferate, some of them indefinitely, while maintaining the ability to differentiate into a few or any cell lineages. In 2003, a group headed by Hans R. Schöler reported that oocyte-like cells could be produced from mouse embryonic stem (ES) cells in vitro. After more than 10 years, where have these researches reached? Which are the major successes achieved and the problems still remaining to be solved? Although during the last years, many reviews have been published about these topics, in the present work, we will focus on an aspect that has been little considered so far, namely a strict comparison between the in vitro and in vivo developmental capabilities of the primordial germ cells (PGCs) isolated from the embryo and the PGC-like cells (PGC-LCs) produced in vitro from different types of stem cells in the mouse, the species in which most investigation has been carried out. Actually, the formation and differentiation of PGCs are crucial for both male and female gametogenesis, and the faithful production of PGCs in vitro represents the basis for obtaining functional germ cells.

Cell Death and Disease (2015) 6, e1906; doi:10.1038/cddis.2015.265; published online 15 October 2015

\section{Facts}

- Some stages of gametogenesis occurring in the embryo or foetus have been reproduced and significant progress in obtaining mature oocytes and spermatozoa from postnatal gonads in vitro were already achieved.

- The capability of stem cell-derived PGC-LCs to give rise to functional gametes has been investigated in a few papers with partial positive results.

- The artificial germ cells produced from mouse pluripotent stem cells proved to be functional as they were capable to differentiate into spermatozoa and oocytes that can give rise to live progeny.

\section{Open Questions}

-What are the main differences between embryo- or foetusderived PGCs and stem cell-derived PGC-LCs?
- Whether artificial germ cells can be utilized for medical purpose for human in the future?

- Are those viable progeny produced from stem cell-derived gametes true healthy individuals?

- Whether in vitro conditions are sufficient for PGC-LCs entering into meiosis and completing epigenetic reprogramming?

From the first work by Hübner et al. in $2003,{ }^{1}$ showing that oocyte-like cells (OLCs) could be produced from mouse embryonic stem (ES) cells in vitro, derivation of germ cells from stem cells raised great public sensation, inspiring hopes in some, fears in others. ${ }^{2-7}$ The Hübner's study and those that followed definitively dispelled the already unsteady myth of the unique and mysterious characteristics of the germline. Actually, in mammals, germ cells derive from the mortal soma and non-continuous germline do exist. Many researchers devoting to the germ cell biology were, however, surprised by some of these results. In fact, artificial germ cells produced in the Hübner's paper and in others that rapidly followed uncovered in vitro developmental capabilities that were not

\footnotetext{
${ }^{1}$ Institute of Reproductive Sciences, Qingdao Agricultural University, Qingdao 266109, China; ${ }^{2}$ Key Laboratory of Animal Reproduction and Germplasm Enhancement in Universities of Shandong, College of Animal Science and Technology, Qingdao Agricultural University, Qingdao 266109, China and ${ }^{3}$ Department of Biomedicine and Prevention, University of Rome 'Tor Vergata', Rome 00133, Italy

*Corresponding author: M De Felici, Department of Biomedicine and Prevention, University of Rome 'Tor Vergata', Rome 00133, Italy. Tel: +39 06 7259 6156; Fax: +39 06 7259 6172; E-mail: defelici@uniroma2.it

or W Shen, Key Laboratory of Animal Reproduction and Germplasm Enhancement in Universities of Shandong, College of Animal Science and Technology, Qingdao Agricultural University, 700 Changcheng Road, Chengyang, Qingdao 266109, China. Tel: +86 05328803 0246; Fax: +86 053286080773 ; E-mail: wshen@qau.edu.cn or shenwei427@163.com

${ }^{4}$ These authors contributed equally to this work.

Abbreviations: ES, embryonic stem; PGCs, primordial germ cells; PGC-LC, PGC-like cells; OLCs, oocyte-like cells; iPS, induced pluripotent stem; dpc, days post coitum; dpp, days postpartum; BMP, bone morphogenetic proteins; WNT3, wingless-type 3; KL, kit ligand; RA, retinoic acid; EG, embryonic germ; GSK3, glycogen synthase kinase 3; ERK, extracellular signal regulated kinase; AGM, aorta-gonad-mesonephros; ActA, Activin A; SSCs, spermatogonial stem cell; GFP, green fluorescent protein; OSCs, oogonia stem cells; EBs, embryoid bodies; SDSCs, skin-derived stem cells; EpiLCs, epiblast-like cells, EpiSCs, epiblast stem cells

Received 18.6.15; revised 01.8.15; accepted 04.8.15; Edited by D Aberdam
} 
shown by true germ cells. Oocytes and sperm seemed to magically appear in the culture dish, although scientists of reproductive biology know that gametogenesis is a very complex process of which only some stages can be reconstructed in vitro. At the same time, however, they were fascinated by these results for two main reasons. First, once validated, in vitro model of gametogenesis from stem cells could make it easier to study and elucidate the mechanisms underlying gametogenesis, mainly in the humans, in which experimental approaches are limited. Second, artificial germ cells could greatly improve and make the actual procedures of assisted reproductive technology more efficient and develop alternative infertility treatments. A scenario for radical changes in the reproduction performance of many species, first of all humans, could also be imagined with consequences difficult to foresee. Actually, from Hübner's work, many papers described the production of germ cells from various types of stem cells, even includes humans. ${ }^{8}$ Particularly important, some authors reported the generation of live offspring from male and female germ cell-like cells obtained in vitro from mouse ES and induced pluripotent stem (iPS) cells. ${ }^{9,10}$ As both male and female germline begins from primordial germ cell (PGCs), precise information about the characteristics and developmental capability of the embryo-derived PGCs and their counterpart, PGC-like cells (PGC-LCs) produced in vitro from stem cells, is essential to elucidate the conditions for obtaining functional germ cells. The present review is focused on this topic.

\section{Brief Outline of Mouse Gametogenesis}

In the attempt to produce germ cells or recreate gametogenesis phases in vitro, it is essential to establish the type and the developmental stage of the putative germ cell generated. As most of the studies reviewed here have been performed in the mouse, we summarized a brief outline of murine gametogenesis and key genes involved in germ cell formation and their roles during gametogenesis, as shown in Table 1.

In the mouse embryo, PGC precursors arise around $6.25 \mathrm{dpc}$ from the proximal epiblast. Subsequently, the precursors move into the extraembryonic allantois mesoderm where they are specified as PGCs. From $8.0 \mathrm{dpc}$, PGCs migrate into the embryo proper, moving through the hindgut and the dorsal mesentery and around $10.0 \mathrm{dpc}$ begin to colonize the gonadal ridges. Germ cell proliferation occurs throughout the migratory period, and continues for 2-3 days after gonad entering, forming a population of about 25000 cells at $13.5 \mathrm{dpc}$ when proliferation terminates. ${ }^{11}$ As many mitoses do not end with cytokinesis, germ cells give rise to small cell clusters termed cysts or nests. Subsequently, they either cease mitosis and enter meiosis becoming primary oocytes (dictyate or germinal vesicle stage) in the female or progressively arrest in G0/G1 as prospermatogonia/ gonocytes in the male.

In the female, around birth, oocytes arrest at the diplotene stage of the meiotic prophase I, and undergo a loss of more than one-third of their number by apoptosis and/or autophagy. ${ }^{12,13}$ Subsequently, the surviving oocytes are individually encircled by pregranulosa cells and finally enclosed into a primordial follicle. The primordial follicle pool represents the ovarian reserve from which cohorts of follicles are continuously activated from birth to menopause to undergo extensive growth and development as primary and secondary follicles in a process termed folliculogenesis.

In the male, transformation of gonocytes into SSCs occurs between 0 and $6 \mathrm{dpp}$, with the first appearance of biologically active SSCs occurring at approximately 3-4 dpp. ${ }^{14}$ The first round of spermatogenesis is completed by puberty and continues up to 1-2 years of age. ${ }^{15}$ The seminiferous cords of the testis of an adult mouse contain cell types in three principal phases of spermatogenesis lasting as whole for 33-35 days: ${ }^{16,17}$ spermatogonial renewal and proliferation, meiosis, and spermiogenesis.

\section{In Vitro and In Vivo Gametogenesis from Embryo-Derived PGCs}

The process of female or male gametogenesis from the formation of PGCs to functional oocytes or sperm has not been entirely recreated in vitro in any mammalian species. However, some stages of this process occurring in the embryo or foetus have been reproduced and significant progresses in obtaining mature gametes from postnatal gonads in vitro were achieved. At present, the more promising approaches for producing functional gametes from PGCs are based on in vivo transplantation of PGC-containing tissues collected from embryos or after in vitro reaggregation of PGCs with somatic gonadal cells, into the gonads of prepuberal/adult hosts.

In vitro derivation of PGCs from epiblast. In 2005, Ohinata et al. $^{18}$ devised a robust in vitro culture protocol to induce the differentiation of epiblast cells into PGC-LCs. They added BMPs and WNT3 to the culture dish of isolated floating epiblasts and monitored PGC formation using transgenic fluorescent reporter genes whose expression is controlled by the upstream regulatory elements of the genes encoding Prdm1 (also known as Blimp1) or Prdm14, which are

Table 1 The role of key genes involved in germ cell formation

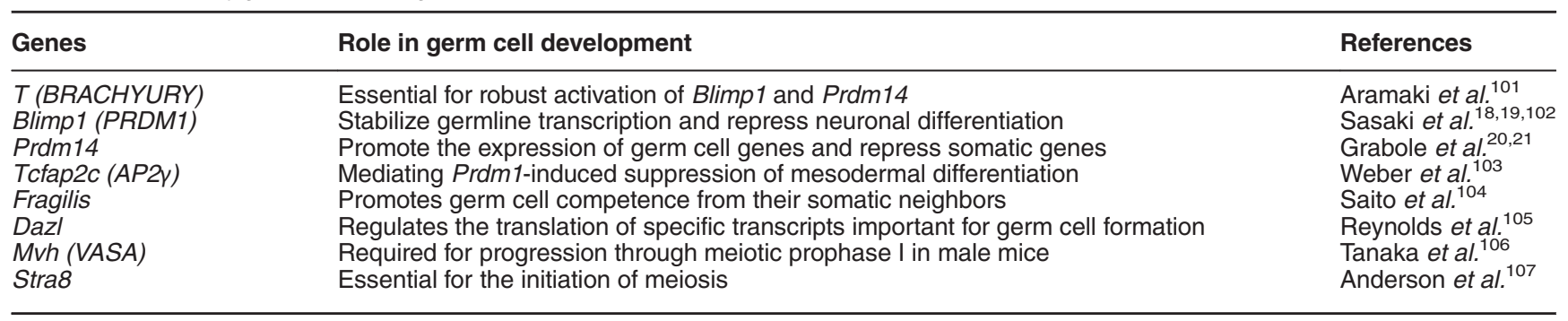


expressed in PGC precursors. ${ }^{18-21}$ They showed that epiblast cells, in which these reporters were induced, expressed germ cell-specific genes in an appropriate sequence and displayed chromatin modifications characteristic resembling in vivo germ cells. Most importantly, they also demonstrated that male PGC-LCs, like endogenous PGCs, were able to differentiate into spermatozoa when transplanted into testicular tubules of prepuberal mice and even to fertilize oocytes to produce viable mice.

Oocytes and EG cells from in vitro cultured and isolated PGCs. Usually mouse PGCs obtained from 11.5 to $12.5-d p c$ gonadal ridges can be maintained in culture only for 3-4 days before undergoing degeneration through apoptosis (Figures 1 and 2). ${ }^{22,23}$ Although the cell monolayers were considered necessary to support PGC survival and proliferation over this time, Farini and her collaborators ${ }^{24}$ showed that they were not necessary for their entering into meiosis in vitro. Actually, these authors showed that both female and male PGCs with minimal gonadal cell contamination were able to enter and progress into meiotic prophase I up to pachytene/diplotene when providing a cocktail of growth factors. On the other hand, it has been previously shown that mouse PGCs maintained onto embryonic fibroblast monolayers for 7-10 days in the continuous presence of a combination of growth factors, deviated from their normal differentiation pathways and gave rise to colonies of ES-like cells termed EG cells. ${ }^{25-27}$ Such behaviour was much more frequent in pregonadal (8.5-10.5 $\mathrm{dpc}=$ about $18 / 100)$ than in gonadal $(11.5-12.5 \mathrm{dpc}=$ about $3 / 100)$ PGCs and resembled the transformation of PGCs in embryonic carcinoma cells occurring in the foetal testis of certain mouse strains. ${ }^{28}$ Similarly, EG cells were derived from human PGCs. ${ }^{29}$ More recently, it has been shown that mouse PGCs can also give rise to EG cells in the absence of cell monolayers when they were cultured onto fibronectin and in the presence of GSK3 and ERK kinase inhibitors (2i). ${ }^{30,31}$

As far as we know, only one paper has shown that pregonadal male or female PGCs mixed with endogenous somatic cells of the $10.5 \mathrm{dpc}$ AGM region when cultured onto $\mathrm{KL}$-producing cell monolayer were able to enter and progress into meiotic prophase I following a timing comparable with the in vivo situation. ${ }^{32}$ In partial disagreement with such results, Farini et al. reported that although isolated $10.5 \mathrm{dpc}$ PGCs were able to engage meiosis and express meiotic genes such as Sycp3, Dmc1 and Rec8, these PGCs appeared unable to progress beyond the leptotene stage after 5 days of culture. PGCs of the same age, however, were able to enter and progress into the meiotic prophase $\mathrm{I}$ if cultured within an intact $A G M$.

The capability of the primary oocytes produced in vitro from female PGCs to continue their development and be enclosed into follicles was not studied. Indirect data indicate, however, that they could be able to begin the growing phase in vitro also without the companion pregranulosa cells but not to form

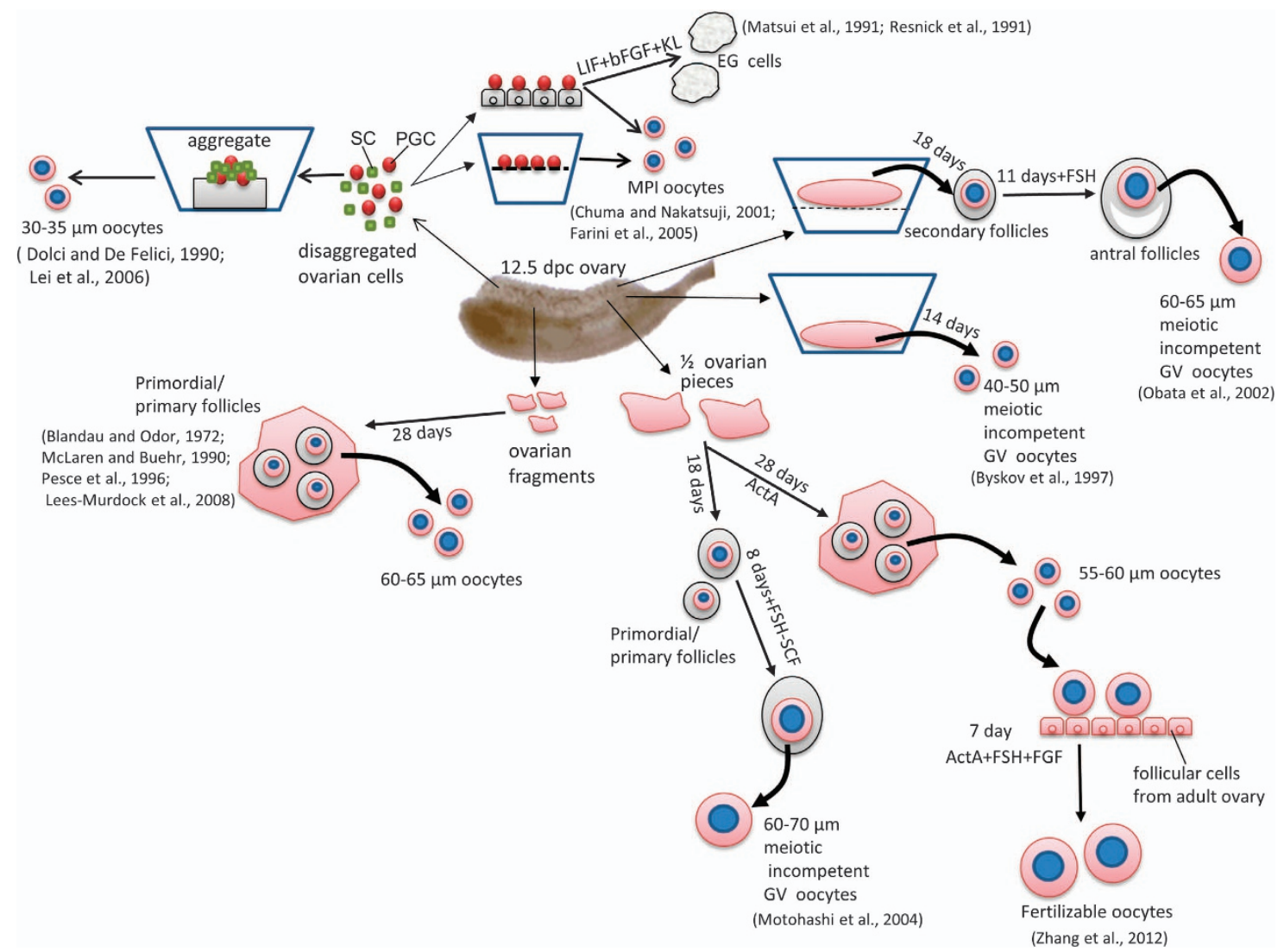

Figure 1 A schematic representation of the main experimental approaches and results used to reproduce in vitro oogenesis stages from premeiotic female mouse PGCs (for details, see text) 


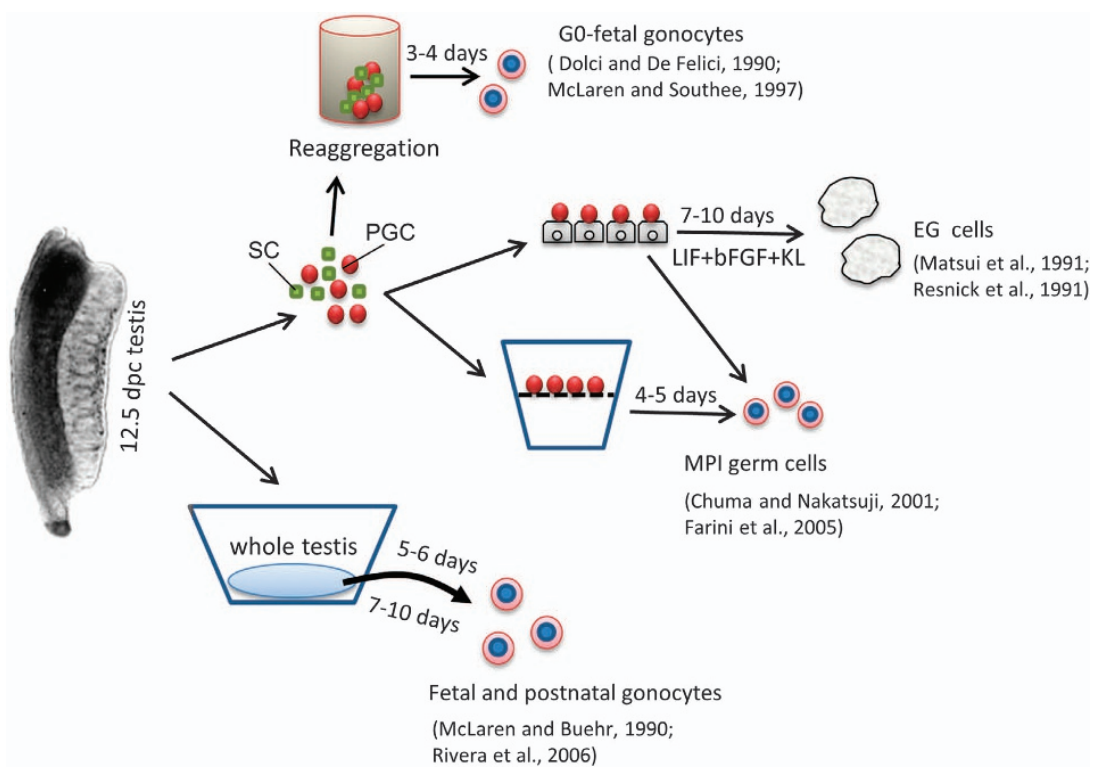

Figure 2 A schematic representation of the main experimental approaches and results used to reproduce in vitro spermatogenesis stages from 12.5-dpc male mouse PGCs (for details, see text)

follicles with ovarian somatic cells. In fact, Klinger and De Felici ${ }^{33}$ showed that primary oocytes isolated from the foetal ovaries entered the growth phase upon stimulation with $\mathrm{KL}$, while Lei et al. ${ }^{34}$ observed that 12.5-dpc PGCs after 10-11 days of culture developed into primary oocytes, but were unable to form follicles when aggregated with gonadal somatic cells.

Overall, these experiments indicate that both isolated female and male gonadal PGCs in vitro are able to enter and progress into meiotic prophase I when the right cocktail of growth factors is provided. In any case, the microenvironment of the developing gonadal ridges seems necessary for gonadal PGCs acquiring meiotic competence and capability to enter and progress into the meiotic prophase I.

Oocytes and gonocytes from in vitro cultured PGCs inside gonadal tissues. The developmental capability of female PGCs maintained in vitro within their gonadal tissues was investigated following basically three experimental approaches: organotypic culture, culture of pieces of ovarian tissues or PGC-somatic cell aggregates (Figures 1 and 2).

As far as we know, the more advanced developmental phases of oogenesis obtained using organotypic in vitro culture of mouse embryonic ovaries were the preantral and antral follicle stage.$^{35-37}$ In particular, Obata and collaborators obtained follicles from $12.5 \mathrm{dpc}$ ovaries via a two-step in vitro culture system. ${ }^{37}$ Noteworthy, Germinal vesicle oocytes obtained from such follicles reached a diameter of $60-65 \mu \mathrm{m}$ but were unable to resume meiosis.

Several authors cultured whole or pieces of embryonic ovaries allowing them to attach and spread onto the bottom of the culture dish. ${ }^{38-42}$ In such cultures, mouse PGCs were able to efficiently form primary oocytes capable to be assembled into primordial or primary follicles. Within these structures, oocytes grew considerably to reach a diameter around 65-70 $\mu \mathrm{m}$, but did not acquire the capability to resume and complete meiosis as normally do their in vivo counterparts. Recently, Zhang et al. ${ }^{42}$ reported, however, that a small number of such oocytes, when ActA was present in the medium throughout the entire culture time, were able to resume meiosis and be fertilized.

Finally, in a third experimental approach, female PGCs isolated and aggregated with gonadal cells of the same or other ages or different cell types, were found to enter meiosis and give rise to primary oocytes of $30-35 \mu \mathrm{m}$ diameter. These cells were, however, unable to form follicles or to further progress into the growing phase in vitro. ${ }^{34,38,43}$

These in vitro experiments emphasize that it is relatively simple to induce the development of female PGCs into primary oocytes inside cultured ovarian tissues in vitro. Moreover, they indicate that the most part of these oocytes are capable to complete the meiotic prophase I and to begin and almost complete the growing phase independently from proper folliculogenesis. However, under the in vitro conditions devised so far, even the oocytes reaching full growth rarely acquire complete meiotic maturation and fertilizability and never the capacity to support embryo developmental after fertilization.

Little information is available about the developmental capability of male PGCs in vitro cultured within embryonic testis or testicular tissues. Early papers showed that $12.5-d p c$ male PGCs aggregated with their own or different type of somatic cells entered G0 arrest as prospermatogonia as they normally do in vivo. ${ }^{38,43}$ On the other hand, male PGCs obtained from 11.5-dpc gonadal ridges entered into meiosis when aggregated with their own gonadal cells or lung cells. ${ }^{44}$ Similarly, PGCs cultured within intact 12.5 -dpc testis underwent G0 arrest but entered meiosis in 11.5-dpc gonadal ridges if testis cords do not properly form. ${ }^{38,45}$ Once formed, prospermatogonia are able to survive for several days in organotypic cultures and to reach developmental stages comparable with postnatal gonocytes. ${ }^{46}$ However, whether 
male PGCs from such culture conditions are capable of spermatogenesis remains unknown.

Actually, it was also proven complicated to reconstruct the entire mammalian spermatogenesis in vitro from postnatal spermatogonia. Interestingly, new methods have been only recently published reporting complete spermatogenesis in vitro from postnatal or prepuberal mouse gonocytes/ spermatogonia. Sato et al. ${ }^{47}$ showed that tissue fragments of neonatal mouse testes, which contain only gonocytes or primitive spermatogonia, can produce spermatids and sperm in vitro under serum-free culture conditions. The obtained spermatids and spermatozoa resulted in healthy and reproductively competent offspring through intracytoplasmic fertilization. Using the same method, these authors reported spermatogenesis also from SSCs. ${ }^{48}$ Another method based on three-dimensional testicular cell culture in soft agar has been recently described to allow the progression of prepuberal spermatogonia into meiosis and further maturation of the germ cells into morphologically normal spermatozoa, although with very low efficiency. ${ }^{49}$

These last results suggest that once and if male PGCs are induced to differentiate into postnatal gonocytes/spermatogonia, complete spermatogenesis could be accomplished in vitro using such methods.

Oocytes and sperm from in vivo transplanted PGCs. A number of papers showed that ovaries reconstructed by aggregating premeiotic female PGCs with ovarian somatic cells and transplanted into the kidney capsule or the ovarian bursa of syngeneic hosts are able to form preantral and antral follicles and develop into meiotic competent and even fertilizable oocytes (Figure 3). ${ }^{34,50,51}$ In this regard, it is important to point out that the developmental stage of the ovary from which PGCs are isolated and the proper synchronization of the germ cell-somatic cell interactions are crucial for germ cell survival and completion of oogenesis after transplantation. In fact, Nicholas et al. ${ }^{50}$ found that in transplanted reconstructed ovaries before $13.5 \mathrm{dpc}$, PGCs completed prophase I of meiosis but did not survive and form follicles. The same results were obtained when 12.5-dpc PGCs were aggregated with somatic cells from foetal ovaries of later developmental stages, and these PGCs are competent to form follicles after kidney capsule transplantation or in vitro culture. ${ }^{34,50}$ However, other papers cited above ${ }^{52,53}$ reported that aggregates of 12.5 -dpc ovarian cells were able to produce fertilizable oocytes.

More recently, Zhang et al. ${ }^{54}$ injected fluorescent GFPovarian cells obtained from $12.5-\mathrm{dpc}$ foetuses directly into the ovaries of adult recipient females. After 2 months, they found a significant number of preantral and antral follicles showing both GFP-positive oocyte and surrounding granulosa cells. Zou et al. ${ }^{55}$ reported that putative mouse OSCs can produce live offspring when transplanted into the ovaries of adult females. Similar results were also observed in human when putative OSCs isolated from reproductive-age women were injected into adult human ovarian cortical tissue biopsies and further transplanted into immunodepressed female mice. ${ }^{56}$ These results demonstrated that not only the ovary environment is obviously crucial for supporting proper oogenesis but also that oogenesis processes normally occurring during the foetal and early postnatal ages can occur in the postnatal ovary or even in ectopic sites in adult individuals. ${ }^{57-59}$

The capability of pregonadal and gonadal male PGCs to undergo spermatogenesis upon in vivo transplantation was investigated in a few papers (Figure 4). Previous works showed that 12.5-15.5-dpc mouse testes were capable to reorganize into testicular structures with spermatogenesis or seminiferous tubules with teratomas when transplanted under the capsule of adult testes. ${ }^{60,61}$ Following the seminal work of Brinster et al., ${ }^{62}$ which showed that the transplantation of spermatogonia from donor mice to the testes of infertile recipient mice results in donor-derived spermatogenesis. Chuma et al. ${ }^{63}$

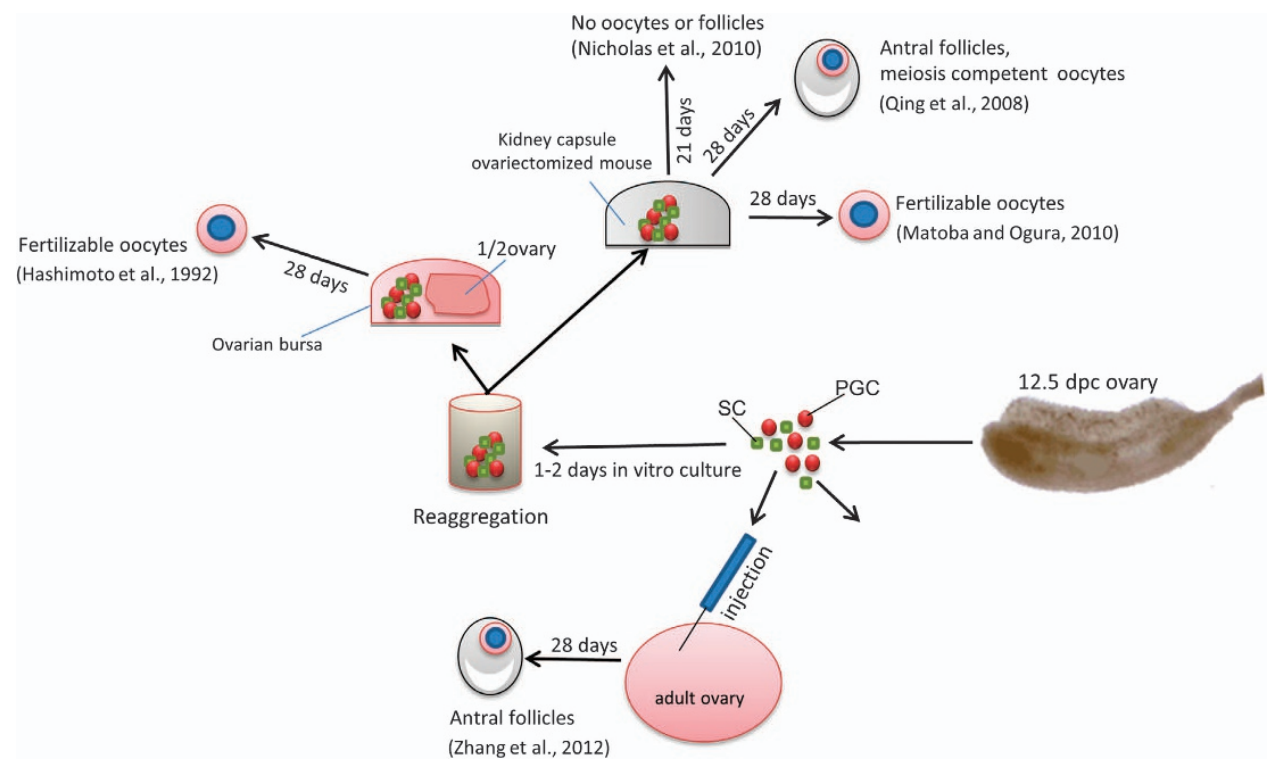

Figure 3 A schematic representation of the main experimental approaches and results used to reproduce in vivo oogenesis stages from premeiotic female mouse PGCs (for details, see text) 


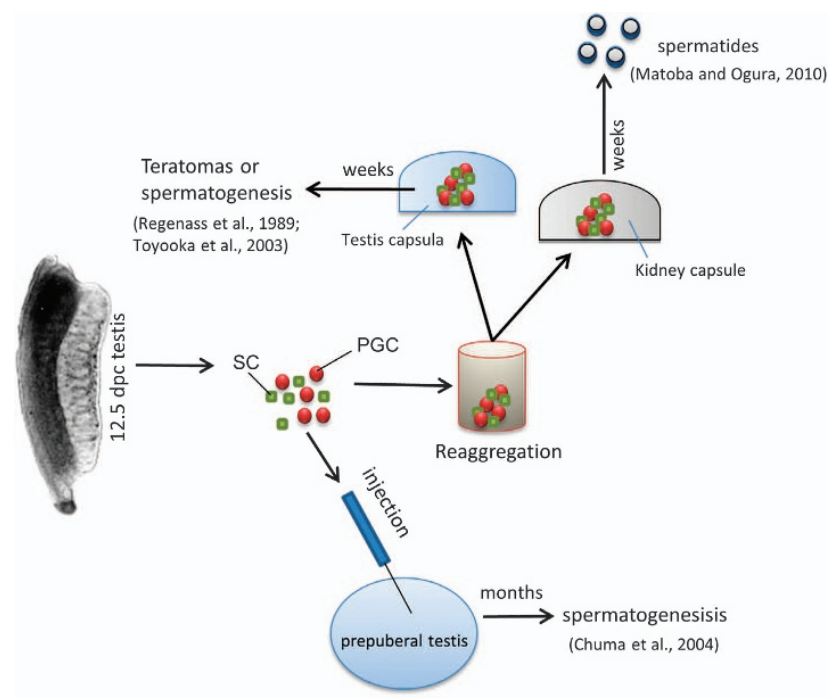

Figure 4 A schematic representation of the main experimental approaches and results used to reproduce in vivo spermatogenesis stages from 12.5-dpc male mouse PGCs (for details, see text)

reported that male epiblast cells and PGCs were surprisingly able to establish colonies of spermatogenesis after transfer into the seminiferous tubules of infertile prepuberal mice. Matoba and Ogura $^{53}$ reported that spermatids can be obtained from 12.5-dpc male PGCs when transplanted under kidney capsules of adult mice; significantly, these spermatids can give rise to live offspring when injected into normal oocytes.

Although the development of male PGCs transplanted into adult testes into teratomas or differentiating germ cells seems critically affected by the donor genotype, the findings reported above unequivocally indicate that they may exhibit remarkable spatial and temporal flexibility in development, as long as they remain under in vivo conditions. Particularly important, the postnatal testis tubules, at least up to puberty, appear able to provide the male PGCs the proper microenvironment to accomplish their complete maturation process from the epiblast to postnatal spermatogonial stem cells.

\section{In Vitro and In Vivo Gametogenesis from PGC-Like Cells}

From the ground-breaking work of Hübner et al. ${ }^{1}$ until that of Hayashi et al. ${ }^{9,10}$ several papers claimed to have derived PGC-like cells from different types of stem cells ranging from ES to iPS cells and adult stem cells. A detailed description and discussion of these papers is beyond the scope of the present work and can be found elsewhere. ${ }^{2,4-6,64-70}$ Briefly, the PGC induction methods frequently include: (i) The formation of EBs and the use of growth factors known to induce PGC differentiation from the epiblast such as BMP4 and WNT3 (in some studies, PGC-LCs appeared to form spontaneously from EBs, see for example Geijsen et al., ${ }^{71}$ Vincent et al. ${ }^{72}$ ); (iii) overexpression of key genes that regulate germ cell formation, such as Dazl and Mvh genes; ${ }^{73,74}$ and (iii) conditioned media containing unidentified PGCLCOinducing factors (Figure 5). ${ }^{75,76}$ Most of these studies had, however, some or several drawbacks. For example, the lack of markers that unequivocally allow to distinguish PGCs from stem cells and the precise molecular characterization of the PGC-LCs produced in vitro. Most importantly, as we will discuss in the next paragraphs, the capability of these PGC-LCs to give rise to functional gametes was investigated in a few papers with partial positive results only.

Between 2011 and 2012, the papers by Hayashi et al. ${ }^{9,10}$ established a protocol that can be so far considered the golden standard for derivation of PGCs from ES and iPS cells. In this procedure, stem cells were first differentiated into a novel type of cells harbouring the post-implantation epiblast status, called epiblast-like cells (EpiLCs); after induction with a cocktail of other growth factors, EpiLCs robustly (about 30\%) differentiated into PGC-LCs resembling their in vivo counterparts. Using a similar method, PGC-LCs have been recently obtained from human ES cells. ${ }^{8}$ Interestingly, the Saitou's group also reported that without growth factors, simultaneous overexpression of three transcription factors, Blimp1, Prdm14 and Tfap2c (also known as AP2 ), directed mouse EpiLCs swiftly and efficiently into a PGC state. ${ }^{77}$ An apparent improvement of the original Hayashi's method has been recently reported. ${ }^{78}$ As we will discuss below, Hayashi et al. notably reported that PGC-LCs were capable to differentiate into fertile sperm and oocytes after in vivo transplantation.

Oocytes and male germ cells from isolated PGC-like cells in vitro. As far as we know, no papers have convincingly shown that PGC-LCs are able to undergo normal meiotic prophase in vitro. In fact, although several authors reported the expression of meiotic genes and proteins by these cells such as SCP3, $\gamma \mathrm{H} 2 \mathrm{AX}$ or DMC1, in a few of them, in which such capability was investigated by observing the typical morphological pattern of the meiotic chromosomes, severe abnormalities were reported. ${ }^{79-81}$

Despite such results, in the early Hübner's study and in a number of subsequent papers, the formation of follicle-like structures or OLCs from stem cells in the culture dish was observed. ${ }^{52,76,80,82-85}$ Particularly surprising is the formation of aggregates resembling cumulus-oocyte complexes from either female or male foetal porcine or newborn mouse SDSCs. ${ }^{75,86-90}$ In all cases, however, the OLCs showed morphological and molecular abnormalities and were not proved to be functional. Our interpretation is that under certain in vitro conditions, some types of stem cells can acquire morphological and molecular features of oocytes independently from meiosis and proper follicle assembly. ${ }^{91}$ A recent paper supports such a possibility. In fact, Dokscin et al. ${ }^{92}$ showed that mouse oocyte growth and differentiation are dissociable from the chromosomal events of meiosis; they observed that a few surviving Stra8-deficient female germ cells grown and differentiated into OLCs that synthesized zona pellucida, assembled into follicles and were even ovulated and fertilized without meiotic initiation, and noteworthy, these oocytes arrested at the two-cell stage after in vitro fertilization.

Several papers reported the formation of haploid male germ cells in vitro resembling round spermatids or even with a sperm-like morphology from mouse $e^{71,82,93,94}$ and human $^{73,74,95-97}$ ES, iPS cells and adult stem cells. The efficiency of such processes was, however, very low and when tested, the haploid cells proved to be only partly functional. In fact, in the mouse, two papers showed that haploid cells 


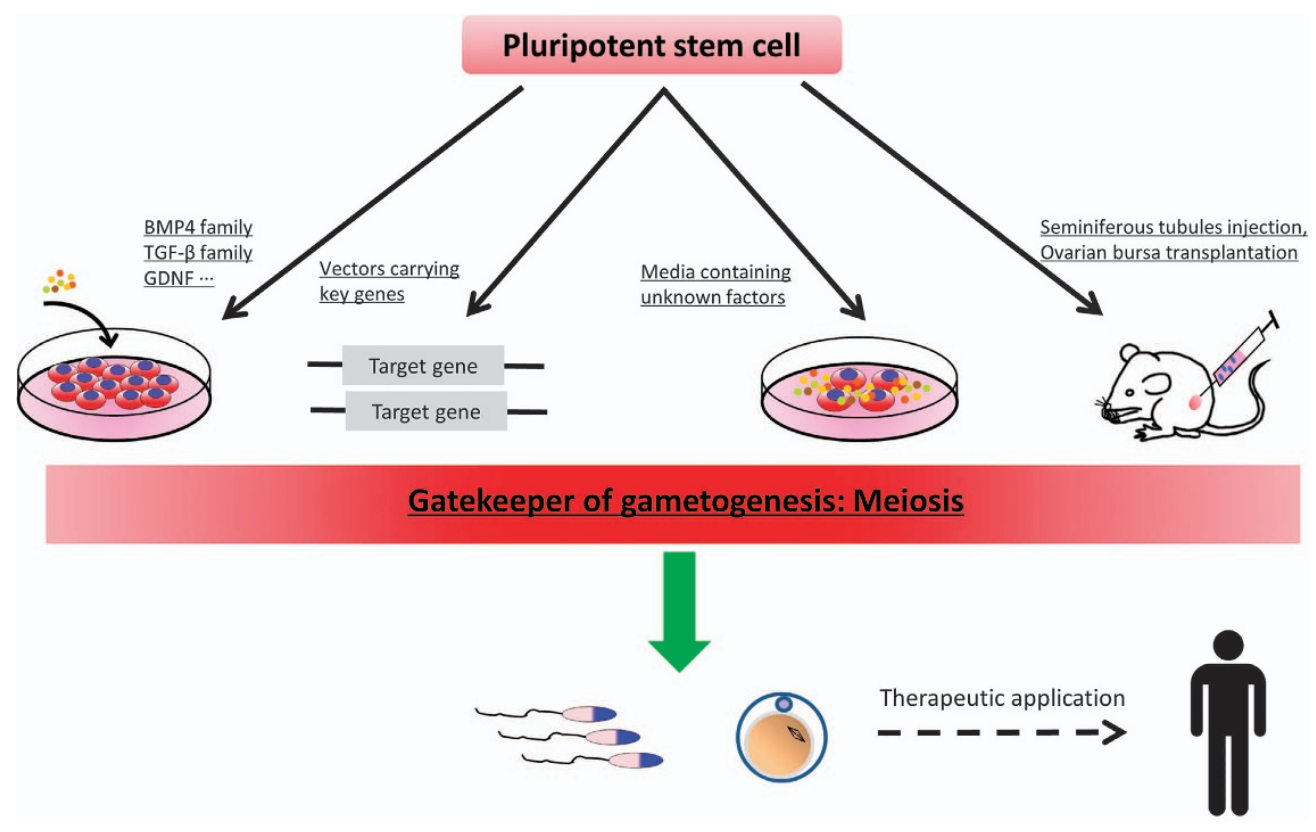

Figure 5 Methods used for germ cell induction and potential medical application

generated in vitro were able to fertilize oocytes. Geijsen et al. ${ }^{71}$ detected and isolated haploid cells from mouse EBs treated with RA, and showed that the injection of the cells into oocytes resulted in the formation of blastocyst-like structures at a low rate. Nayernia et al. ${ }^{93}$ reported the induction of haploid cells with a sperm-like morphology from ES cell monolayers and successful production of offspring by intracytoplasmic injection which had growth abnormalities and died within 5 months after birth.

Oocytes and gonocytes from in vitro cultured PGC-like cells inside gonadal tissues. As reported above, various experimental approaches indicate that it is relatively simple to induce the development of embryo-derived female PGCs into primary growing oocytes within in vitro cultured embryonic ovarian tissues. Under certain culture conditions, such oocytes are able to form follicles and in rare cases to complete the growing phase and be fertilized. ${ }^{42}$ In all cases, however, the OLCs inside these structures showed morphological and molecular abnormality and were not proved to be functional.

As far as we know, the only attempt to culture PGC-LCs in vitro within embryo-derived ovarian tissue has been reported by Hayashi and Surani. ${ }^{98}$ Stella-GFP-positive PGCLCs obtained from EpiSCs were mixed with gonadal cells from 12.5-dpc ovaries, and after centrifugation, the cell suspension was left to aggregate and seeded through the gaps present between small pieces of 12.5-dpc ovaries on transwell inserts. After 40 days in culture, OLCs with strong expression of Stella-GFP indistinguishable from the endogenous germ cell present in the same co-cultures were observed although with very low frequency around 1 oocyte/5000 PGC-LCs.

The available information on male embryo-derived PGCs in vitro cultured within testis tissues apart for their ability to differentiate into prospermatogonia or gonocytes did not account for their capability to undergo spermatogenesis. Likely for this inability and the difficulties in reconstructing spermatogenesis in vitro were discussed in the previous paragraph; no attempts have been performed to maintain male PGC-LCs in vitro for a long time within testis tissues or onto Sertoli cell monolayers. In the works in which male PGC-LCs were identified and maintained in EBs up to the haploid status, we can postulate that such formation might develop into a testis-like structure in which PGC-LCs can differentiate at a certain extent.

The new methods allowing spermatogenesis in cultured postnatal or prepuberal gonocytes reported above represent a system to attempt to differentiate XY PGC-LCs to postnatal gonocytes/spermatogonia and even to accomplish complete in vitro spermatogenesis.

Oocytes and sperm derived from in vivo transplanted PGC-LCs. Because as reported above, a number of papers showed that embryo-derived female PGCs, at least from $13.5 \mathrm{dpc}$ onward, when aggregated with ovarian somatic cells and transplanted under the kidney capsule or ovarian bursa of syngeneic mice were able to give rise to fertilizable oocytes, some authors used this approach to investigate whether PGC-LCs possess such capability.

Nicholas et al. ${ }^{80}$ co-aggregated GFP-PGC-LCs obtained from mouse ES cells with dissociated newborn mouse ovarian tissues. After transplantation under the kidney capsule of recipient mice, the authors found some GFP oocytes within primary follicles in two of the grafts. Similar results were obtained by Dyce et al. and Chuang et al. ${ }^{90,99}$ Hayashi et al. published the most efficient method to obtain oocytes after aggregation of GFP-PGC-LCs obtained from mouse EpiLCs (see above) with 12.5-dpc ovarian cells and in vivo transplantation under the ovarian bursa of host mice. These authors reported an efficiency of about $0.7 \%$ fully grown oocyte generated after 4 weeks in a synchronous single wave of oogenesis from both female PGC-LCs and embryo-derived PGCs. 
Hayashi et al. ${ }^{9}$ also reported that male PGC-LCs from EpiLCs, like embryo-derived PGCs, ${ }^{63}$ were capable to differentiate into spermatozoa when transplanted into seminiferous tubules of prepuberal mice. Such spermatozoa gave rise to healthy individuals through in vitro microinsemination. Zhu et al. ${ }^{100}$ reported that male germ cells produced from mouse iPS cell EBs were able to differentiate into male germ cells ranging from spermatogonia to round spermatids after transplantation into recipient testes. Toyooka et al. ${ }^{61}$ should be credited for the first successful generation of spermatozoa from male PGC-LCs. The authors using BMP4 to induce germ cells from EBs, reported that male PGC-LCs were able to differentiate into spermatozoa in aggregates with gonadal cells from 12.5-dpc testis when transplanted under a host testis capsule. However, the capability of these cells to fertilize was not investigated.

\section{Conclusions}

The artificial germ cells produced in the mouse proved to be functional because they were capable to differentiate into spermatozoa and oocytes that give rise to healthy individuals. In this regard, the behaviour of the mouse PGC-LCs was quite similar to that of embryo-derived PGCs. However, these still showed some notable differences from their in vivo counterparts. Although the reasons of such differences are not clear, these results indicate that PGC-LCs are not identical to embryo-derived PGCs and suggest that the gonadal ridges produce factor(s) essential for PGC survival/proliferation and differentiation. Therefore, it is not surprising that both artificial and real PGCs require to be enclosed inside or re-aggregated with suitable somatic cells to progress through gameto genesis. However, culture conditions suitable to complete oogenesis and spermatogenesis in vitro have not been established yet.

Generally, two processes that are the most difficult to be reconstructed in isolated PGC-LCs in vitro are the proper entry and progression into the meiosis and the epigenetic changes accompanying both female and male gametogenesis. Determining whether epigenesis and meiosis occur correctly during the process of deriving germ cells from stem cells is obviously crucial for the acquisition of proper gamete functionality. Nevertheless, the apparent failure of stem cell-derived germ cells to undergo meiosis efficiently could provide opportunities to study the molecular mechanisms regulating meiotic entry, progression and further broaden insights into the causes of meiotic failure.

As a prerequisite to the establishment of gametogenesis in vitro, we must first achieve a comprehensive understanding of the mechanisms underlying gametogenesis in vivo. Only the elucidation of the many still unknown aspects of such complex process and the progress in the coculture methods to maintain germ cells for long periods in vitro in 3-D microenvironments, suitable for the different stage-dependent requirements of gametogenesis, will give the necessary tools for rendering the production of germ cells from stem cells a reliable possibility. The first steps for producing germ cells from stem cells in vitro are promising, but there is still a long road ahead.

\section{Conflict of Interest}

The author declares no conflict of interest.

Acknowledgements. This work was supported by National Basic Research Program of China (973 Program, 2012CB944401), National Nature Science Foundation (31171376 and 31471346), Program for New Century Excellent Talents in University (NCET-12-1026) and the Taishan Scholar Construction Foundation of Shandong Province.

1. Hubner K, Fuhrmann G, Christenson LK, Kehler J, Reinbold R, De La Fuente R et al. Derivation of oocytes from mouse embryonic stem cells. Science 2003; 300: 1251-1256.

2. Newson AJ, Smajdor AC. Artificial gametes: new paths to parenthood? J Med Ethics 2005; 31: 184-186.

3. Scholer HR, Wu G. Oocytes originating from skin? Nat Cell Biol 2006; 8: 313-314.

4. Hua J, Sidhu K. Recent advances in the derivation of germ cells from the embryonic stem cells. Stem Cells Dev 2008; 17: 399-411.

5. Hayashi K, Saitou M. Perspectives of germ cell development in vitro in mammals. Anim Sci J 2014; 85: 617-626.

6. Handel MA, Eppig JJ, Schimenti JC. Applying 'gold standards' to in-vitro-derived germ cells. Cell 2014; 157: 1257-1261.

7. Magnusdottir E, Surani MA. How to make a primordial germ cell. Development 2014; 141: 245-252.

8. Irie N, Weinberger L, Tang WW, Kobayashi T, Viukov S, Manor YS et al. SOX17 is a critical specifier of human primordial germ cell fate. Cell 2015; 160: 253-268.

9. Hayashi K, Ohta H, Kurimoto K, Aramaki S, Saitou M. Reconstitution of the mouse germ cell specification pathway in culture by pluripotent stem cells. Cell 2011; 146: 519-532.

10. Hayashi K, Ogushi S, Kurimoto K, Shimamoto S, Ohta H, Saitou M. Offspring from oocytes derived from in vitro primordial germ cell-like cells in mice. Science 2012; 338 971-975.

11. Tam PP, Snow MH. Proliferation and migration of primordial germ cells during compensatory growth in mouse embryos. J Embryol Exp Morphol 1981; 64 133-147.

12. Lobascio AM, Klinger FG, Scaldaferri ML, Farini D, De Felici M. Analysis of programmed cell death in mouse fetal oocytes. Reproduction 2007; 134: 241-252.

13. De Felici M, Klinger FG, Farini D, Scaldaferri ML, Iona S, Lobascio M. Establishment of oocyte population in the fetal ovary: primordial germ cell proliferation and oocyte programmed cell death. Reprod Biomed Online 2005; 10: 182-191.

14. Oatley JM, Brinster RL. Regulation of spermatogonial stem cell self-renewal in mammals. Annu Rev Cell Dev Biol 2008; 24: 263-286.

15. Sakai Y, Suetake I, Shinozaki F, Yamashina S, Tajima S. Co-expression of de novo DNA methyltransferases Dnmt3a2 and Dnmt3L in gonocytes of mouse embryos. Gene Expr Patterns 2004; 5: 231-237.

16. Hecht NB, Bower PA, Waters SH, Yelick PC, Distel RJ. Evidence for haploid expression of mouse testicular genes. Exp Cell Res 1986; 164: 183-190.

17. Oakberg EF. Duration of spermatogenesis in the mouse. Nature 1957; 180: 1137-1138.

18. Ohinata Y, Payer B, O'Carroll D, Ancelin K, Ono Y, Sano M et al. Blimp1 is a critical determinant of the germ cell lineage in mice. Nature 2005; 436: 207-213.

19. Kurimoto K, Yabuta Y, Ohinata Y, Shigeta M, Yamanaka K, Saitou M. Complex genomewide transcription dynamics orchestrated by Blimp1 for the specification of the germ cell lineage in mice. Genes Dev 2008; 22: 1617-1635.

20. Yamaji M, Seki Y, Kurimoto K, Yabuta Y, Yuasa M, Shigeta M et al. Critical function of Prdm14 for the establishment of the germ cell lineage in mice. Nat Genet 2008; 40 : 1016-1022.

21. Grabole N, Tischler J, Hackett JA, Kim S, Tang F, Leitch HG et al. Prdm14 promotes germline fate and naive pluripotency by repressing FGF signalling and DNA methylation. EMBO Rep 2013; 14: 629-637.

22. De Felici M. Twenty years of research on primordial germ cells. Int J Dev Biol 2001; 45: 519-522.

23. De Felici M, Scaldaferri ML, Lobascio M, Iona S, Nazzicone V, Klinger FG et al. Experimental approaches to the study of primordial germ cell lineage and proliferation Hum Reprod Update 2004; 10: 197-206.

24. Farini D, Scaldaferri ML, Iona S, La Sala G, De Felici M. Growth factors sustain primordial germ cell survival, proliferation and entering into meiosis in the absence of somatic cells. Dev Biol 2005; 285: 49-56.

25. Resnick JL, Bixler LS, Cheng L, Donovan PJ. Long-term proliferation of mouse primordial germ cells in culture. Nature 1992; 359: 550-551.

26. Matsui $Y$, Zsebo K, Hogan BL. Derivation of pluripotential embryonic stem cells from murine primordial germ cells in culture. Cell 1992; 70: 841-847.

27. Moe-Behrens GH, Klinger FG, Eskild W, Grotmol T, Haugen TB, De Felici M. Akt/PTEN signaling mediates estrogen-dependent proliferation of primordial germ cells in vitro. Mol Endocrinol 2003; 17: 2630-2638. 
28. Donovan PJ. The germ cell-the mother of all stem cells. Int J Dev Biol 1998; 42 1043-1050.

29. Shamblott MJ, Axelman J, Wang S, Bugg EM, Littlefield JW, Donovan PJ et al. Derivation of pluripotent stem cells from cultured human primordial germ cells. Proc Natl Acad Sci USA 1998; 95: 13726-13731.

30. Leitch HG, Blair K, Mansfield W, Ayetey H, Humphreys P, Nichols J et al. Embryonic germ cells from mice and rats exhibit properties consistent with a generic pluripotent ground state. Development 2010; 137: 2279-2287.

31. Leitch HG, Nichols J, Humphreys P, Mulas C, Martello G, Lee C et al. Rebuilding pluripotency from primordial germ cells. Stem Cell Rep 2013; 1: 66-78.

32. Nakatsuji N, Chuma S. Differentiation of mouse primordial germ cells into female or male germ cells. Int J Dev Biol 2001; 45: 541-548.

33. Klinger FG, De Felici M. In vitro development of growing oocytes from fetal mouse oocytes: stage-specific regulation by stem cell factor and granulosa cells. Dev Biol 2002; 244 $85-95$.

34. Lei L, Zhang H, Jin S, Wang F, Fu M, Wang $\mathrm{H}$ et al. Stage-specific germ-somatic cell interaction directs the primordial folliculogenesis in mouse fetal ovaries. J Cell Physiol 2006; 208: 640-647.

35. Obata Y, Kono T, Hatada I. Gene silencing: maturation of mouse fetal germ cells in vitro. Nature 2002; 418: 497.

36. Dong HS, Li L, Song ZH, Tang J, Xu B, Zhai XW et al. Premeiotic fetal murine germ cells cultured in vitro form typical oocyte-like cells but do not progress through meiosis. Theriogenology 2009; 72: 219-231.

37. Song Z, Min L, Pan Q, Shi Q, Shen W. Maternal imprinting during mouse oocyte growth in vivo and in vitro. Biochem Biophys Res Commun 2009; 387: 800-805.

38. McLaren A, Buehr M. Development of mouse germ cells in cultures of fetal gonads. Cell Differ Dev 1990; 31: 185-195

39. Pesce M, Cerrito MG, Travia G, Russo MA, De Felici M. In vitro development of growing oocytes from fetal and early postnatal mouse ovaries. Int J Dev Biol 1996; : 229S-230S.

40. Byskov AG, Guoliang X, Andersen CY. The cortex-medulla oocyte growth pattern is organized during fetal life: an in-vitro study of the mouse ovary. Mol Hum Reprod 1997; 3 : 795-800.

41. Lees-Murdock DJ, Lau HT, Castrillon DH, De Felici M, Walsh CP. DNA methyltransferase loading, but not de novo methylation, is an oocyte-autonomous process stimulated by SCF signalling. Dev Biol 2008; 321: 238-250.

42. Zhang ZP, Liang GJ, Zhang XF, Zhang GL, Chao HH, Li L et al. Growth of mouse oocytes to maturity from premeiotic germ cells in vitro. PloS One 2012; 7: e41771.

43. De Felici M, Dolci S. Cellular interactions of mouse fetal germ cells in in vitro systems. Curr Top Dev Biol 1987; 23: 147-162.

44. McLaren A, Southee D. Entry of mouse embryonic germ cells into meiosis. Dev Biol 1997; 187: 107-113.

45. Byskov AG, Saxen L. Induction of meiosis in fetal mouse testis in vitro. Dev Biol 1976; 52 193-200.

46. Livera G, Delbes G, Pairault C, Rouiller-Fabre V, Habert R. Organotypic culture, a powerful model for studying rat and mouse fetal testis development. Cell Tissue Res 2006; 324 507-521.

47. Sato $\mathrm{T}$, Katagiri $\mathrm{K}$, Yokonishi T, Kubota $\mathrm{Y}$, Inoue $\mathrm{K}$, Ogonuki $\mathrm{N}$ et al. In vitro production of fertile sperm from murine spermatogonial stem cell lines. Nat Commun 2011; 2 : 472.

48. Sato $T$, Katagiri $K$, Kubota $\mathrm{Y}$, Ogawa $\mathrm{T}$. In vitro sperm production from mouse spermatogonial stem cell lines using an organ culture method. Nat Protoc 2013; 8 : 2098-2104.

49. Abu Elhija M, Lunenfeld E, Schlatt S, Huleihel M. Differentiation of murine male germ cells to spermatozoa in a soft agar culture system. Asian J Androl 2012; 14: 285-293.

50. Nicholas CR, Haston KM, Pera RA. Intact fetal ovarian cord formation promotes mouse oocyte survival and development. BMC Dev Biol 2010; 10: 2.

51. Koichiro H, Motoko N, Nakatsuji N. Mouse offspring derived from fetal ovaries or reaggregates which were cultured and transplanted into adult females. Development, Growth \& Differentiation 1992; 34: 233-238.

52. Qing T, Shi Y, Qin H, Ye X, Wei W, Liu H et al. Induction of oocyte-like cells from mouse embryonic stem cells by co-culture with ovarian granulosa cells. Differentiation 2007; 75: 902-911.

53. Matoba S, Ogura A. Generation of functional oocytes and spermatids from fetal primordial germ cells after ectopic transplantation in adult mice. Biol Reprod 2011; 84: 631-638.

54. Zhang H, Zheng W, Shen Y, Adhikari D, Ueno H, Liu K. Experimental evidence showing that no mitotically active female germline progenitors exist in postnatal mouse ovaries. Proc Natl Acad Sci USA 2012; 109: 12580-12585.

55. Zou K, Yuan Z, Yang Z, Luo H, Sun K, Zhou L et al. Production of offspring from a germline stem cell line derived from neonatal ovaries. Nat Cell Biol 2009; 11: 631-636.

56. White YA, Woods DC, Takai Y, Ishihara O, Seki H, Tilly JL. Oocyte formation by mitotically active germ cells purified from ovaries of reproductive-age women. Nat Med 2012; 18 413-421.

57. Chen B, Zhang L, Tang J, Feng X, Feng Y, Liang G et al. Recovery of functional oocytes from cultured premeiotic germ cells after kidney capsule transplantation. Stem Cells Dev 2013; 22: 567-580.
58. Shen W, Li L, Bai Z, Pan Q, Ding M, Deng H. In vitro development of mouse fetal germ cells into mature oocytes. Reproduction 2007; 134: 223-231.

59. Shen W, Zhang D, Qing T, Cheng J, Bai Z, Shi $Y$ et al. Live offspring produced by mouse oocytes derived from premeiotic fetal germ cells. Biol Reprod 2006; 75: 615-623.

60. Regenass U, Friedrich TD, Stevens LC. Experimental induction of testicular teratomas in dissociated-reaggregated chimaeric gonads. J Embryol Exp Morphol 1982; 72: 153-167.

61. Toyooka Y, Tsunekawa N, Akasu R, Noce T. Embryonic stem cells can form germ cells in vitro. Proc Natl Acad Sci USA 2003; 100: 11457-11462.

62. Brinster RL, Zimmermann JW. Spermatogenesis following male germ-cell transplantation. Proc Natl Acad Sci USA 1994; 91: 11298-11302.

63. Chuma S, Kanatsu-Shinohara M, Inoue K, Ogonuki N, Miki H, Toyokuni S et al. Spermatogenesis from epiblast and primordial germ cells following transplantation into postnatal mouse testis. Development 2005; 132: 117-122.

64. Surani MA. Stem cells: how to make eggs and sperm. Nature 2004; 427: 106-107.

65. Aflatoonian B, Moore H. Germ cells from mouse and human embryonic stem cells. Reproduction 2006; 132: 699-707.

66. Wu MY, Chow SN. Derivation of germ cells from mouse embryonic stem cells. J Formos Med Assoc 2005; 104: 697-706.

67. West JA, Daley GQ. In vitro gametogenesis from embryonic stem cells. Curr Opin Cell Biol 2004; 16: 688-692.

68. Oktem O, Oktay K. Stem cells: a perspective on oocytes. Ann NY Acad Sci 2008; 1127: 20-26.

69. Marques-Mari Al, Lacham-Kaplan O, Medrano JV, Pellicer A, Simon C. Differentiation of germ cells and gametes from stem cells. Hum Reprod Update 2009; 15: 379-390.

70. Volarevic V, Bojic S, Nurkovic J, Volarevic A, Ljujic B, Arsenijevic N et al. Stem cells as new agents for the treatment of infertility: current and future perspectives and challenges. Biomed Res Int 2014; 2014: 507234.

71. Geijsen N, Horoschak M, Kim K, Gribnau J, Eggan K, Daley GQ. Derivation of embryonic germ cells and male gametes from embryonic stem cells. Nature 2004; 427 : 148-154.

72. Vincent JJ, Li Z, Lee SA, Liu X, Etter MO, Diaz-Perez SV et al. Single cell analysis facilitates staging of Blimp1-dependent primordial germ cells derived from mouse embryonic stem cells. PloS One 2011; 6: e28960.

73. Kee K, Angeles VT, Flores M, Nguyen HN, Reijo Pera RA. Human DAZL, DAZ and BOULE genes modulate primordial germ-cell and haploid gamete formation. Nature 2009; 462: 222-225.

74. Medrano JV, Ramathal C, Nguyen HN, Simon C, Reijo Pera RA. Divergent RNA-binding proteins, DAZL and VASA, induce meiotic progression in human germ cells derived in vitro. Stem Cells 2012; 30: 441-451.

75. Dyce PW, Liu J, Tayade C, Kidder GM, Betts DH, Li J. In vitro and in vivo germ line potential of stem cells derived from newborn mouse skin. PloS One 2011; 6: e20339.

76. Lacham-Kaplan $\mathrm{O}$, Chy H, Trounson A. Testicular cell conditioned medium supports differentiation of embryonic stem cells into ovarian structures containing oocytes. Stem Cells 2006; 24: 266-273.

77. Nakaki F, Hayashi K, Ohta H, Kurimoto K, Yabuta Y, Saitou M. Induction of mouse germ-cell fate by transcription factors in vitro. Nature 2013; 501: 222-226.

78. Li Y, Wang X, Feng X, Liao S, Zhang D, Cui X et al. Generation of male germ cells from mouse induced pluripotent stem cells in vitro. Stem Cell Res 2014; 12: 517-530.

79. Tedesco M, Desimio MG, Klinger FG, De Felici M, Farini D. Minimal concentrations of retinoic acid induce stimulation by retinoic acid 8 and promote entry into meiosis in isolated pregonadal and gonadal mouse primordial germ cells. Biol Reprod 2013; 88: 145.

80. Nicholas CR, Haston KM, Grewall AK, Longacre TA, Reijo Pera RA. Transplantation directs oocyte maturation from embryonic stem cells and provides a therapeutic strategy for female infertility. Hum Mol Genet 2009; 18: 4376-4389.

81. Novak I, Lightfoot DA, Wang H, Eriksson A, Mahdy E, Hoog C. Mouse embryonic stem cells form follicle-like ovarian structures but do not progress through meiosis. Stem Cells 2006; 24: 1931-1936.

82. Kerkis A, Fonseca SA, Serafim RC, Lavagnolli TM, Abdelmassih S, Abdelmassih R et al. In vitro differentiation of male mouse embryonic stem cells into both presumptive sperm cells and oocytes. Cloning Stem Cells 2007; 9: 535-548.

83. Danner S, Kajahn J, Geismann C, Klink E, Kruse C. Derivation of oocyte-like cells from a clonal pancreatic stem cell line. Mol Hum Reprod 2007; 13: 11-20.

84. Salvador LM, Silva CP, Kostetskii I, Radice GL, Strauss JF 3rd. The promoter of the oocyte-specific gene, Gdf9, is active in population of cultured mouse embryonic stem cells with an oocyte-like phenotype. Methods 2008; 45: 172-181.

85. Yu Z, Ji P, Cao J, Zhu S, Li Y, Zheng L et al. Dazl promotes germ cell differentiation from embryonic stem cells. J Mol Cell Biol 2009; 1: 93-103.

86. Dyce PW, Shen W, Huynh E, Shao H, Villagomez DA, Kidder GM et al. Analysis of oocyte-like cells differentiated from porcine fetal skin-derived stem cells. Stem Cells Dev 2011; 20: 809-819.

87. Dyce PW, Wen L, Li J. In vitro germline potential of stem cells derived from fetal porcine skin. Nat Cell Biol 2006; 8: 384-390.

88. Park BW, Shen W, Linher-Melville K, Li J. Deleted in azoospermia-like enhances in vitro derived porcine germ cell formation and meiosis. Stem Cells Dev 2013; 22 : 939-950. 
89. Shen W, Park BW, Toms D, Li J. Midkine promotes proliferation of primordial germ cells by inhibiting the expression of the deleted in azoospermia-like gene. Endocrinology 2012; 153: 3482-3492.

90. Park BW, Pan B, Toms D, Huynh E, Byun JH, Lee YM et al. Ovarian-cell-like cells from skin stem cells restored estradiol production and estrus cycling in ovariectomized mice. Stem Cells Dev 2014; 23: 1647-1658.

91. Sun YC, Cheng SF, Sun R, Zhao Y, Shen W. Reconstitution of gametogenesis in vitro: meiosis is the biggest obstacle. J Genet Genomics 2014; 41: 87-95.

92. Dokshin GA, Baltus AE, Eppig JJ, Page DC. Oocyte differentiation is genetically dissociable from meiosis in mice. Nat Genet 2013; 45: 877-883.

93. Nayernia K, Nolte J, Michelmann HW, Lee JH, Rathsack K, Drusenheimer N et al. In vitrodifferentiated embryonic stem cells give rise to male gametes that can generate offspring mice. Dev Cell 2006; 11: 125-132.

94. Lue Y, Erkkila K, Liu PY, Ma K, Wang C, Hikim AS et al. Fate of bone marrow stem cells transplanted into the testis: potential implication for men with testicular failure. Am J Pathol 2007; 170: 899-908.

95. Eguizabal C, Montserrat N, Vassena R, Barragan M, Garreta E, Garcia-Quevedo L et al. Complete meiosis from human induced pluripotent stem cells. Stem Cells 2011; 29: 1186-1195.

96. Panula S, Medrano JV, Kee K, Bergstrom R, Nguyen HN, Byers B et al. Human germ cell differentiation from fetal- and adult-derived induced pluripotent stem cells. Hum Mol Genet 2011; 20: 752-762.

97. Easley CA 4th, Phillips BT, McGuire MM, Barringer JM, Valli H, Hermann BP et al. Direct differentiation of human pluripotent stem cells into haploid spermatogenic cells. Cell Rep 2012; 2: 440-446.

98. Hayashi K, Surani MA. Self-renewing epiblast stem cells exhibit continual delineation of germ cells with epigenetic reprogramming in vitro. Development 2009; 136: 3549-3556.

99. Chuang CY, Lin KI, Hsiao M, Stone L, Chen HF, Huang YH et al. Meiotic competent human germ cell-like cells derived from human embryonic stem cells induced by BMP4/WNT3A signaling and OCT4/EpCAM (epithelial cell adhesion molecule) selection. J Biol Chem 2012; 287: 14389-14401.

100. Zhu Y, Hu HL, Li P, Yang S, Zhang W, Ding H et al. Generation of male germ cells from induced pluripotent stem cells (iPS cells): an in vitro and in vivo study. Asian J Androl 2012; 14: $574-579$
101. Aramaki S, Hayashi K, Kurimoto $\mathrm{K}$, Ohta H, Yabuta $\mathrm{Y}$, Iwanari $\mathrm{H}$ et al. A mesodermal factor, T, specifies mouse germ cell fate by directly activating germline determinants. Dev Cell 2013; 27: 516-529.

102. Weber S, Eckert D, Nettersheim D, Gillis AJ, Schafer S, Kuckenberg P et al. Critical function of AP-2gamma/TCFAP2C in mouse embryonic germ cell maintenance. Biol Reprod 2010; 82: 214-223.

103. Sasaki K, Yokobayashi S, Nakamura T, Okamoto I, Yabuta Y, Kurimoto K et al. Robust in vitro induction of human germ cell fate from pluripotent stem cells. Cell Stem Cell 2015; 17: 178-194.

104. Saitou M, Barton SC, Surani MA. A molecular programme for the specification of germ cell fate in mice. Nature 2002; 418: 293-300.

105. Reynolds N, Collier B, Maratou K, Bingham V, Speed RM, Taggart M et al. Dazl binds in vivo to specific transcripts and can regulate the pre-meiotic translation of Mvh in germ cells. Hum Mol Genet 2005; 14: 3899-3909.

106. Tanaka SS, Toyooka Y, Akasu R, Katoh-Fukui Y, Nakahara Y, Suzuki R et al. The mouse homolog of Drosophila Vasa is required for the development of male germ cells. Genes Dev 2000; 14: 841-853.

107. Anderson EL, Baltus AE, Roepers-Gajadien HL, Hassold TJ, de Rooij DG, van Pelt AM et al. Stra8 and its inducer, retinoic acid, regulate meiotic initiation in both spermatogenesis and oogenesis in mice. Proc Natl Acad Sci USA 2008; 105: 14976-14980.

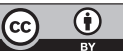

Cell Death and Disease is an open-access journal published by Nature Publishing Group. This work is licensed under a Creative Commons Attribution 4.0 International License. The images or other third party material in this article are included in the article's Creative Commons license, unless indicated otherwise in the credit line; if the material is not included under the Creative Commons license, users will need to obtain permission from the license holder to reproduce the material. To view a copy of this license, visit http://creativecommons.org/licenses/by/4.0/ 